\title{
Mechanisms of inactivation of the tumour suppressor gene RHOA in colorectal cancer
}

Higinio Dopeso ${ }^{1,6}$, Paulo Rodrigues ${ }^{1,6}$, Josipa Bilic ${ }^{1}$, Sarah Bazzocco ${ }^{1}$, Fernando Cartón-García ${ }^{1}$, Irati Macaya ${ }^{1}$, Priscila Guimarães de Marcondes ${ }^{1}$, Estefanía Anguita ${ }^{1}$, Marc Masanas ${ }^{2}$, Lizbeth M Jiménez-Flores ${ }^{1}$, Águeda Martínez-Barriocanal ${ }^{1}$, Rocío Nieto ${ }^{1}$, Miguel F Segura ${ }^{2}$, Simo Schwartz Jr ${ }^{3,4}$, John M Mariadason ${ }^{5}$ and Diego Arango*,1

${ }^{1}$ Group of Biomedical Research in Digestive Tract Tumors, CIBBIM-Nanomedicine, Vall d'Hebron Research Institute (VHIR), Universitat Autònoma de Barcelona (UAB), Barcelona 08035, Spain; ${ }^{2}$ Laboratory of Translational Research in Child and Adolescent Cancer, Vall d'Hebron Research Institute (VHIR)-UAB, Barcelona 08035, Spain; ${ }^{3}$ Drug Delivery and Targeting Group, CIBBIM Nanomedicine, Vall d'Hebron Research Institute (VHIR), Barcelona 08035, Spain; ${ }^{4}$ CIBER de Bioingeniería, Biomateriales y Nanomedicina (CIBER-BBN), Zaragoza 50018, Spain and ${ }^{5}$ La Trobe University School of Cancer Medicine, Olivia Newton-John Cancer Research Institute, Melbourne 3084, VIC, Australia

Background: Reduced RHOA signalling has been shown to increase the growth/metastatic potential of colorectal tumours. However, the mechanisms of inactivation of RHOA signalling in colon cancer have not been characterised.

Methods: A panel of colorectal cancer cell lines and large cohorts of primary tumours were used to investigate the expression and activity of RHOA, as well as the presence of RHOA mutations/deletions and promoter methylation affecting RHOA. Changes in RHOA expression were assessed by western blotting and gPCR after modulation of microRNAs, SMAD4 and c-MYC.

Results: We show here that RHOA point mutations and promoter hypermethylation do not significantly contribute to the large variability of RHOA expression observed among colorectal tumours. However, RHOA copy number loss was observed in $16 \%$ of colorectal tumours and this was associated with reduced RHOA expression. Moreover, we show that miR-200a/b/429 downregulates RHOA in colorectal cancer cells. In addition, we found that TGF- $\beta /$ SMAD4 upregulates the RHOA promoter. Conversely, RHOA expression is transcriptionally downregulated by canonical Wnt signalling through the Wnt target gene c-MYC that interferes with the binding of SP1 to the RHOA promoter in colon cancer cells.

Conclusions: We demonstrate a complex pattern of inactivation of the tumour suppressor gene RHOA in colon cancer cells through genetic, transcriptional and post-transcriptional mechanisms.

The small GTPases of the RHO family, including RHOA, RAC and CDC42, are molecular switches that cycle between a GTP-bound active form and a GDP inactive form, and participate in key aspects of the oncogenic process such as proliferation, polarisation, apoptosis, adhesion, migration, invasion and metastasis (Itoh et al, 1999; Sahai and Marshall, 2002). Activation of RHO proteins is most commonly reported to be oncogenic and has been shown to promote transformation of different cell types (Sahai and Marshall, 2002). However, we have recently shown that RHOA (Ras homologue family member A) has tumour suppressor activity in colorectal cancer and the loss of this GTPase significantly contributes to tumour progression and metastasis, largely through the activation of canonical Wnt signalling (Rodrigues et al, 2014) and low RHOA expression is associated with poor patient

\footnotetext{
*Correspondence: Dr D Arango; E-mail: diego.arango@vhir.org

${ }^{6}$ These authors contributed equally to this work.
}

Received 9 March 2017; revised 25 October 2017; accepted 26 October 2017; published online 5 December 2017

(C) 2018 Cancer Research UK. All rights reserved 0007-0920/18 
prognosis (Arango et al, 2005). Tumour suppressor genes are inactivated during the tumourigenic process by a variety of mechanisms, including genetic and epigenetic alterations, overexpression of regulatory microRNAs or direct transcriptional silencing of the promoter, and the molecular mechanisms regulating the loss of RHOA expression and activity in colorectal cancer cells are not well understood.

Large exome/genome sequencing studies of colorectal tumours have demonstrated low mutation frequency of RHOA in colorectal tumours (Cancer Genome Atlas Network, 2012; Seshagiri et al, 2012). Consistent with the oncogenic activity of RHOA in most tumour types investigated, reduced promoter methylation levels associated with RHOA overexpression have been reported in different tumour types (Braga et al, 2015). In addition, RHOA levels have been shown to be regulated by $m i R-155, m i R-340$ and $m i R$ $200 a / b / 429$ in endothelial cells (Bijkerk et al, 2012), melanocytes (Jian et al, 2014) and hepatocellular carcinoma (Wong et al, 2015), respectively. However, the regulation of RHOA by miRNAs in colorectal cancer cells has not been investigated in detail.

Activation of canonical Wnt signalling and inactivation of TGF$\beta$ signalling play key roles in the initiation and progression of colorectal tumours (Mishra et al, 2005). Both pathways convey extracellular signals from the membrane to the nucleus, regulating the transcription of multiple genes that participate in tumour growth and metastasis. Canonical Wnt signalling is a master regulator of proliferation and differentiation in normal intestinal epithelial cells and colon cancer cells (Mishra et al, 2005). Almost $80-90 \%$ of colorectal tumours have hyperactive Wnt signalling, most frequently because of inactivating mutations in $A P C$ that leads to the nuclear accumulation of $\beta$-catenin and the transcriptional activation of multiple targets, such as c-MYC and Cyclin D1 (Bienz and Clevers, 2000). On the other hand, TGF/SMAD signalling, an important regulator of cell growth and differentiation, is initiated by TGF- $\beta$ superfamily ligands binding to type II TGF- $\beta$ receptors, leading to the activation of SMAD intracellular mediators that translocate then into the nucleus, where they regulate transcription (Moustakas et al, 2001). TGF- $\beta$ signalling is frequently silenced in colorectal tumours through different mechanisms, such as mutations in TGFBR2 or SMAD4 (Parsons et al, 1995; Eppert et al, 1996; Alazzouzi et al, 2005).

In this study, we found that multiple mechanisms contribute to the inactivation of RHOA signalling in colorectal cancer cells. The loss of the chromosomal region containing RHOA (3p21) was associated with reduced expression of this GTPase. Moreover, $m i R$ $200 a / b / 429$ was found to inhibit the expression of $R H O A$ in colorectal cancer cells. Importantly, we also demonstrate that transcriptional downregulation of $R H O A$ through the TGF- $\beta$ and Wnt signalling pathways is an important mechanism contributing to the inactivation of RHOA signalling.

\section{MATERIALS AND METHODS}

Cell lines and plasmids. The LS174T/W4, LS174T/dnTCF4, LS174T/sißCAT, SW480/ADH, HCT8/S11 and HCT116$\mathrm{SMAD}^{-/-}$were kindly provided by other researchers, as detailed in the Supplementary Methods. Other cell lines used in this study (LIM2405, HCT116, RKO, SK-CO-1, SW837 and HEK293T) were obtained from the American Type Culture Collection (ATCC, Manassas, VA, USA). All plasmids used are described in the Supplementary Methods.

Luciferase reporter assays. Renilla luciferase (pRL-TK; Promega, Madison, WI, USA) was used as a control for transfection efficiency in luciferase reporter assays using the Dual-Luciferase Assay Kit (Promega).
Western blot and RHOA activity determination. The GTPbound RHOA levels and western blotting were carried out as previously described (Rodrigues et al, 2014). The antibodies used are described in the Supplementary Methods.

CpG island methylation assays and microarray analysis. The DNA methylation status in the $1145 \mathrm{bp} \mathrm{CpG}$ island located in the promoter of RHOA was assessed on colon cancer cell lines by methylation-specific PCR (MSP-PCR), bisulphite sequencing and HumanMethylation27 Beadchips (Illumina, San Diego, CA, USA). Relative mRNA levels were determined by microarray analysis (HG-U133 Plus 2.0 chips; Affymetrix, Santa Clara, CA, USA) as previously reported (Bazzocco et al, 2015).

Animal experiments. C57BL/6J-Apc ${ }^{M i n} / \mathrm{J}$ mice were obtained from The Jackson Laboratory (Stock No: 002020, Bar Harbor, ME, USA). All animal experiments were carried out under protocols approved by the Vall d'Hebron Ethical Committee for Animal Experimentation.

Immunohistochemistry and quantitative RT-PCR. The expression of RHOA and SMAD4 in Dukes' C colorectal tumours have been reported before (Alazzouzi et al, 2005; Arango et al, 2005). Total RNA was reverse transcribed and relative levels of the indicated genes were assessed by real-time PCR using SYBR Green Master Mix (Applied Biosystems, Foster City, CA, USA). All primers used are detailed in the Supplementary Methods.

ChIP assay. The RKO cells were treated for $24 \mathrm{~h}$ with $1 \mu \mathrm{M} \mathrm{JQ} 1$ (or vehicle DMSO) and fixed with formaldehyde (Thermo Scientific, Waltham, MA, USA). Cell pellets were resuspended in nuclei lysis buffer and sonicated with a Bioruptor instrument (Diagenode, Liege, Belgium). Then, $200 \mu \mathrm{g}$ of the cleared supernatant was immunoprecipitated with anti-SP1 antibody (Millipore 07-645, Burlington, MA, USA) or unspecific rabbit IgG. After washing, samples were treated with proteinase $\mathrm{K}$ and DNA recovered (Qiagen PCR product purification kit, Hilden, Germany). Relative levels of RHOA, p21 and a negative control (gene desert in chromosome 12) were quantified by real-time PCR as detailed in the Supplementary Methods.

\section{RESULTS}

RHOA expression in colorectal tumours. The expression of the small GTPase RHOA is frequently downregulated (Supplementary Figure 1A) and contributes significantly to the progression of colorectal cancer (Rodrigues et al, 2014). To investigate the mechanisms regulating the expression of RHOA in colorectal cancer cells, we first assessed the RHOA mRNA levels in a panel of 59 colorectal cancer cell lines using RNA sequencing (Mouradov et al, 2014). Significant variability in RHOA expression was observed (Supplementary Figure 2A and Supplementary Table 1) and the mRNA expression levels in a subset of 34 of these cell lines was confirmed by microarray analysis (Bazzocco et al, 2015) (Supplementary Figure 2B; Pearson's $r=0.52$ and $P=0.0018$ ). The levels of RHOA protein were then assessed in a subset of 18 colon cancer cell lines using western blot analysis, confirming a wide range of RHOA expression in colorectal cancer cell lines also at the protein level (Supplementary Figure 2C and Supplementary Table 1). The range of expression in primary colorectal tumours and cell line models was comparable (Supplementary Figure 1B-G). A significant correlation between the levels of RHOA mRNA and protein was observed in colorectal cancer cells (Supplementary Figure 2D; Pearson's $r=0.6$ and $P=0.018$ ). We then used a rhotekin pull-down assay to assess the levels of active RHOA in 18 colorectal cancer cell lines (Supplementary Figure 2C) and observed a significant correlation between total RHOA expression and GTP-bound active RHOA 
(Supplementary Figure 1E and Supplementary Table 1; Pearson's $r=0.53$ and $P=0.025$ ).

Genetic inactivation of RHOA in colorectal tumours. Previous studies have shown that RHOA is not frequently mutated in colorectal tumours (Arango et al, 2005). Meta-analysis of RHOA mutation frequencies in 983 colorectal primary tumours (Cancer Genome Atlas Network, 2012; Seshagiri et al, 2012; Brannon et al, 2014; Giannakis et al, 2016) showed that only $1.0 \%$ (10 out of 983) of colorectal tumours have RHOA mutations and that these are randomly distributed throughout its coding sequence (Supplementary Figure 3). Therefore, the low incidence of mutations observed in $R H O A$ cannot explain the large variability of RHOA levels observed in colorectal tumours. However, RHOA copy number losses in chromosome 3 p 21 affecting $R H O A$ were observed in $16 \%$ (60 of 376) of colorectal tumours from The Cancer Genome Atlas (TCGA) initiative (Cancer Genome Atlas Network, 2012) and this was associated with reduced RHOA expression (Figure 1A and Supplementary Table 2). In good agreement, we observed RHOA losses in $13.8 \%$ (4 out of 30 ) of colorectal cancer cell lines, and this was associated with significantly lower RHOA mRNA expression (Figure $1 \mathrm{~B}$ and Supplementary Table 1). Therefore, deletions of chromosome $3 \mathrm{p} 21$ affecting RHOA could account for the reduced levels of RHOA observed in a subset of colorectal tumours.

Epigenetic inactivation of RHOA in colorectal tumours. Hypermethylation of promoter $\mathrm{CpG}$ islands in the promoter region of tumour suppressor genes is an important mechanism silencing the expression of genes with tumour suppressor activity (Corté et al, 2012). Because the proximal promoter region of RHOA contains a CpG island spanning $>1400$ bp flanking its transcription start site (Supplementary Figure 4), we investigated whether methylation of this region was associated with loss of RHOA expression in colorectal tumours by determining the levels of RHOA promoter methylation in 30 colon cancer cell lines and using publicly available data from 370 primary colorectal tumours (Cancer Genome Atlas Network, 2012) (Supplementary Tables 1 and 2). Quantification of the levels of methylation of $16 \mathrm{CpG}$ dinucleotides in the promoter of RHOA using HumanMethylation450 BeadChip arrays (Illumina) revealed low levels of methylation in colorectal tumours (Supplementary Figure 5A), and this finding was independently confirmed in colorectal cancer cell lines using either bisulphite sequencing of a region of $254 \mathrm{bp}$ containing 15 CpGs flanking the RHOA transcription start site (Figure 1C and Supplementary Figure 6A) or methylation-specific PCR of the same region (Supplementary Figure 6B). Furthermore, no associations were observed between the levels of methylation and expression of RHOA in colorectal cancer cell lines and primary tumours (Figure 1D and E and Supplementary Figure 5B). These results indicate that $R H O A$ promoter methylation does not regulate $R H O A$ expression in colorectal tumours.

Post-transcriptional regulation of RHOA by miRNAs in colorectal tumours. Previous studies in other tumour types have demonstrated regulation of RHOA expression by microRNAs
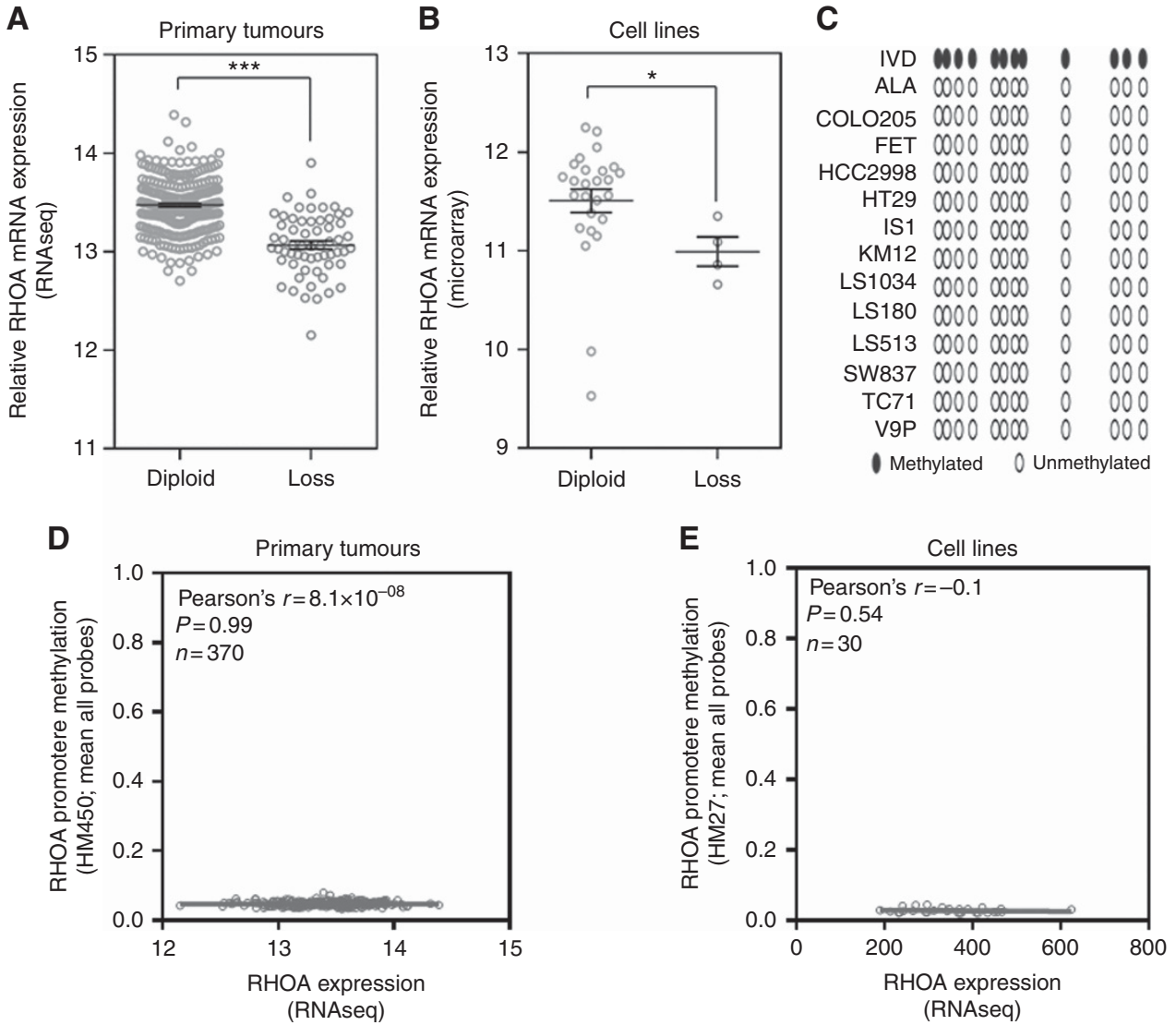

Figure 1. Genetic and epigenetic alterations of RHOA in colorectal tumours. (A and B) Scatter dot plot (and mean \pm s.e.m.) showing RHOA mRNA levels as a function of RHOA copy number in 376 primary colorectal tumours (A) (TCGA) and 30 cell lines (B). (C) Results of bisulphite sequencing in 12 colon cancer cell lines. IVD: in vitro methylated DNA used as control. (D) Correlation between mRNA RHOA expression (RNAseq) and the average methylation of all probes in the RHOA promoter in the HumanMethylation 450 arrays in a cohort of 370 primary colorectal tumours (TCGA). (E) Correlation between mRNA expression (microarray) and average RHOA promoter methylation (HumanMethylation27) in 30 colorectal cancer cell lines. Student's $t$-test ${ }^{\star} P<0.05 ;{ }^{\star \star \star} P<0.0001$. A full colour version of this figure is available at the British Journal of Cancer journal online. 
(Wong et al, 2015). To investigate this in colorectal cancer cells, we used a cohort of 195 primary colorectal tumours where the levels of mRNA and miRNA expression were determined by RNAseq (Cancer Genome Atlas Network, 2012) (Supplementary Table 2). This analysis identified 47 miRNAs whose expression was also significantly negatively correlated with RHOA expression (Supplementary Table 3). In silico analysis predicted evolutionarily conserved binding sites for 14 of these miRNAs (Supplementary Table 3). Importantly, the expression of 12 of these 14 miRNAs was significantly elevated in colorectal tumours compared with the normal colonic mucosa (Supplementary Table 3), suggesting that different miRNAs may contribute to the downregulation of RHOA observed in colorectal tumours.

Of these 14 miRNAs, $m i R-200 b$ and $m i R-429$, which are located in the $m i R-200 a / b / 429$ cluster on chromosome 1 and are transcribed together, showed the highest homology to RHOA (TargetScan), and are highly conserved from Xenopus to humans (Betel et al, 2010). To investigate the possible regulation of RHOA by $m i R-200 a / b / 429$, we transiently co-transfected the $m i R-200 a / b /$ 429 genomic cluster along with a reporter construct expressing luciferase fused to the RHOA 3'-UTR that was either wild type or mutant for the putative $m i R-200 a / b / 429$ binding site. LIM2405 colon cancer cells were used for these experiments as they express low endogenous levels of miR-200a/b/429 (Supplementary Figure 7A). Overexpression of $m i R-200 a / b / 429$ significantly reduced luciferase reporter activity in the cells transfected with the wild-type RHOA 3'-UTR construct compared with the mutant construct (Figure 2A), providing evidence of direct regulation of RHOA expression by these microRNAs. Moreover, stable overexpression of the $m i R-200 a / b / 429$ cluster in LIM2405 cells significantly reduced the endogenous mRNA levels of RHOA, as well as $Z E B 1$, a known target of $m i R-200 a / b / 429$ (Hur et al, 2013) (Figure $2 \mathrm{~B}-\mathrm{D}$ and Supplementary Figure $7 \mathrm{~B}$ ). Collectively, these results demonstrate that the $m i R-200 a / b / 429$ cluster significantly contributes to the downregulation of RHOA observed in colorectal cancer cells. Moreover, we identified additional microRNAs that could further modulate the levels of RHOA in colorectal cancer cells (Supplementary Table 3).

Transcriptional regulation of RHOA in colorectal tumours. Regulation of the activity of the promoter is a key mechanism controlling gene expression. To assess the extent to which RHOA expression is regulated at the transcriptional level we utilised a reporter construct containing the $2 \mathrm{~kb}$ promoter region immediately upstream of the RHOA transcription start site driving the expression of luciferase (Chan et al, 2010). Transient transfection of this reporter construct in 14 colon cancer cell lines revealed significantly higher RHOA promoter activity in cell lines with high endogenous RHOA mRNA expression (Figure 3A), suggesting that regulation of the transcriptional activity of the $R H O A$ promoter is an important mechanism determining the levels of RHOA expression in colorectal cancer cells.

Detailed in silico analysis of the proximal RHOA promoter identified the presence of potential binding sites for at least 57 transcription factors (Supplementary Table 4). To identify physiological regulators of RHOA transcription in colon cancer cells, we correlated the levels of RHOA mRNA with the expression of these transcription factors assessed by RNAseq in a cohort of 244 primary colorectal tumours (TCGA; Supplementary Table 2) (Cancer Genome Atlas Network, 2012). Of the 57 transcription factors with putative binding motifs in the RHOA promoter, the expression of $44(77.2 \%)$ of them was significantly correlated with the expression of RHOA (Supplementary Table 4), suggesting that they may directly regulate $R H O A$ expression in colorectal tumours. Notably, these included binding sites for SMAD4 and c-MYC that are key effectors of the TGF- $\beta$ and Wnt signalling, two of the most commonly deregulated pathways in colorectal cancer.
Transcriptional regulation of RHOA by TGF- $\beta$ signalling in colorectal cancer cells. SMAD4 is a transcription factor regulated by the TGF- $\beta$ pathway and has important tumour suppressor activity in colorectal tumours (Howe et al, 1998; Alazzouzi et al, 2005). SMAD4 mRNA levels showed a significant positive correlation with RHOA mRNA levels in 244 primary colorectal tumours (Supplementary Tables 2 and 4, Figure 3B; Pearson's $\left.r=0.47 ; P=7.97 \times 10^{-15}\right)$. Moreover, quantification of the levels of RHOA (Arango et al, 2005) and SMAD4 (Alazzouzi et al, 2005; Alhopuro et al, 2005) protein by immunohistochemistry in a tissue microarray containing triplicate samples of 162 primary colorectal tumours confirmed a significant association between RHOA and SMAD4 expression (Pearson's $r=0.48 ; P=7.8 \times 10^{-11}$; Figure $3 \mathrm{C}$ ), further suggesting an important role for SMAD4 in the regulation of RHOA expression in these tumours.

To investigate whether TGF- $\beta$ signalling functionally regulates the expression of RHOA, SKCO1 colon cancer cells, which have a functional TGF- $\beta$ signalling pathway (Brunen et al, 2013), were stimulated with TGF- $\beta 1$. As expected, TGF- $\beta 1$ resulted in increased SMAD4 transactivation activity (Figure 3D). In addition, TGF- $\beta 1$ enhanced RHOA promoter activity (Figure 3D) and elevated RHOA mRNA and protein expression (Figure 3E and F). SMAD4 has previously been shown to bind to the RHOA promoter in human embryonic stem cells (Tsankov et al, 2015). Importantly, targeted inactivation of SMAD4 in HCT116 and SKCO1 colon cancer cells resulted in reduced RHOA mRNA levels (Figure $3 \mathrm{G}$ and $\mathrm{H}$ ). These results collectively indicate that RHOA is transcriptional target of SMAD4 in colon cancer cells.

Transcriptional regulation of $\mathrm{RHOA}$ by Wnt signalling in colorectal cancer cells. Canonical Wnt signalling is a master regulator of proliferation and differentiation of both normal intestinal epithelial cells and colon cancer cells (MacDonald et al, 2009). We therefore investigated whether $\mathrm{Wnt} / \beta$-catenin also regulates $\mathrm{RHOA}$ expression using LS174T cells where TCF4/ $\beta$-catenin signalling can be inactivated by doxycycline-dependent overexpression of a dominant negative form of TCF4 (LS174T-dnTCF4) or an shRNA targeting $\beta$-catenin (LS174T-shBCAT) (Van de Wetering et al, 2002). As expected, doxycycline treatment of both LS174T-dnTCF4 and LS174T-shBCAT cells significantly reduced the transcriptional activity of TCF4/ $\beta$-catenin as assessed using a luciferase reporter construct (Supplementary Figure $8 \mathrm{~A}$ and $\mathrm{B}$ ). Importantly, this decrease in TCF $4 / \beta$-catenin activity was associated with increased promoter activity (Figure 4A), mRNA expression (Figure 4B) and protein levels and activity (Figure $4 \mathrm{C}$ ) of RHOA. The transcriptional regulation of $R H O A$ by $\mathrm{TCF} / / \beta$-catenin was further confirmed by transient transfection of dominant negative TCF4 in four additional colon cancer cell lines (SW837, HCT8/S11, SW480/ADH and LS174T/W4; Figure 4D and Supplementary Figure 8C).

In addition, we used a mouse model of intestinal tumourigenesis carrying heterozygous germline $A p c$ mutations ( $A p c^{\text {min }}$ model) (Moser et al, 1990) to assess the effects of Wnt pathway activation on RhoA levels in vivo. Heterozygous Apc mutations in normal intestinal epithelial cells did not affect the levels of RHOA protein (Figure $4 \mathrm{E}$ and $\mathrm{F}$ and Supplementary Figure 8D-F). However, the sporadic loss of the wild-type allele in these cells results in hyperactivation of $\mathrm{Wnt} / \beta$-catenin and the formation of intestinal tumours (Luongo et al, 1994; Sansom et al, 2004) and reduced RhoA expression was observed in the intestinal tumours of $A p c^{\text {min }}$ mice compared with the normal intestinal epithelium of either wild-type or $A p c^{\min }$ mice (Figure $4 \mathrm{E}$ and $\mathrm{F}$ and Supplementary Figure $8 \mathrm{D}-\mathrm{F}$ ). Collectively, these results indicate that RHOA expression is repressed by aberrant Wnt signalling in colorectal cancer cells.

Transcriptional regulation of RHOA by c-MYC in colorectal cancer cells. Because the promoter region of RHOA used for these experiments does not contain binding sites for the TCF4/ $\beta$-catenin transcriptional complex, the effects of Wnt signalling on the 
A

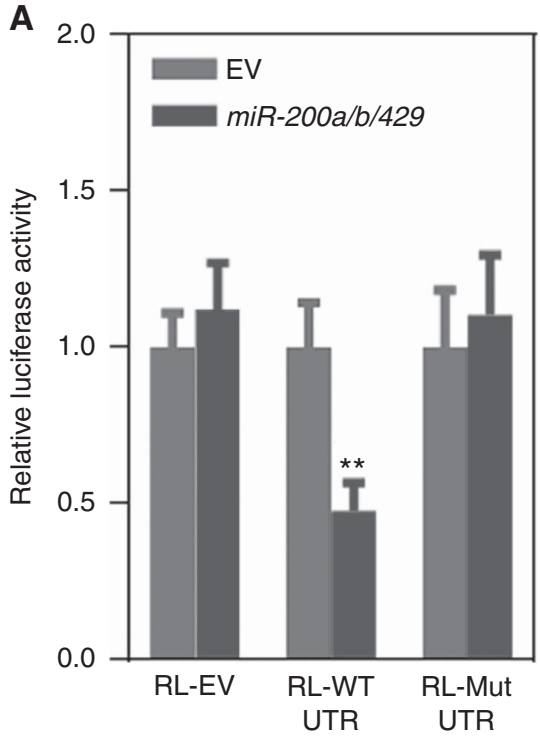

C

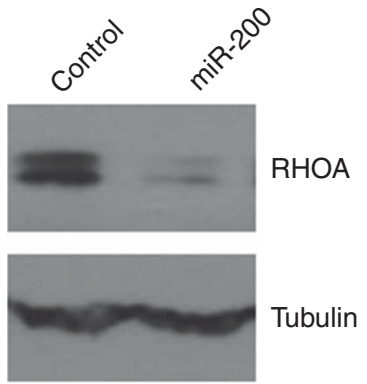

B

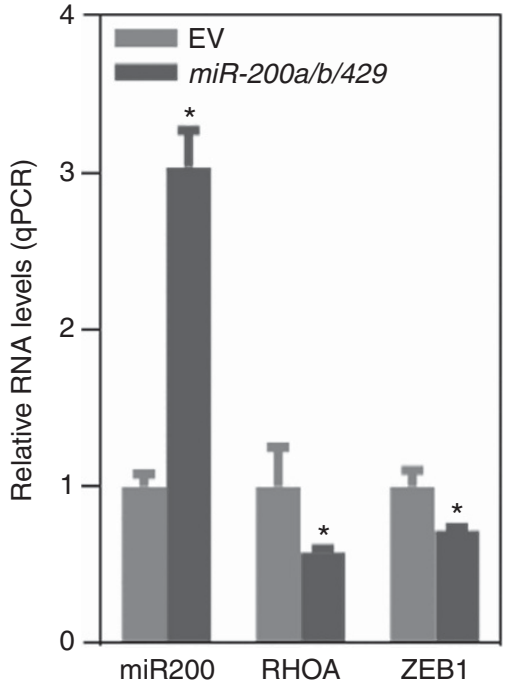

D

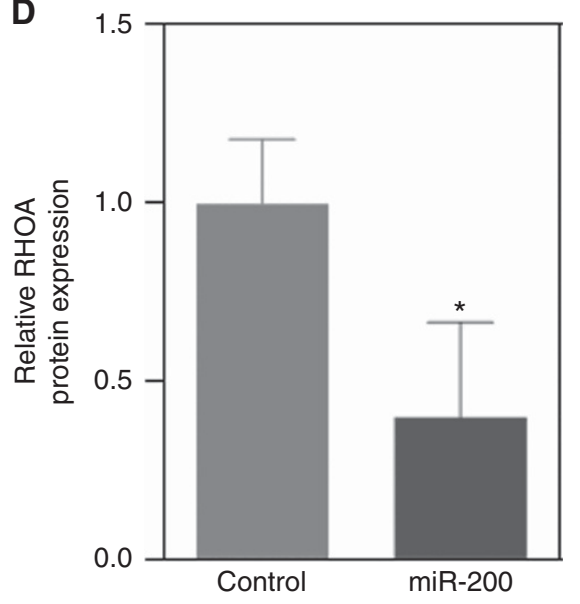

Figure 2. The RHOA expression is regulated by miR-200a/b/429 in colorectal cancer cells. (A) The regulation of RHOA levels by miR-200a/b/429 was assessed using a transient transfection assay with a luciferase reporter gene fused to the $3^{\prime}$-UTR of RHOA containing the wild-type (wt) or a mutant (Mut) miR-200a/b/429 binding site, co-transfected with a vector expressing miR-200a/b/429 or the corresponding empty vector (EV) in LIM2405 colon cancer cells. (B) Stable overexpression of miR-200a/b/429 in LIM2405 colon cancer cells resulted in significant downregulation of the endogenous RHOA mRNA, as well as the known miR-200a/b/429 target gene ZEB1. (C and D) Representative western blot (C) and the mean of three independent experiments (D) showing reduced RHOA protein expression in LIM2405 cells with stable overexpression of miR-200a/b/429. All histograms show the average ( \pm s.e.m.) of three independent experiments. Student's t-test ${ }^{\star} P<0.05 ;{ }^{\star *} P<0.01$. A full colour version of this figure is available at the British Journal of Cancer journal online.

RHOA promoter are likely to be indirect. The c-MYC is an important transcriptional target of TCF4/ $\beta$-catenin and has been reported to regulate the expression of RHOA in prostate and breast cancer cells (Chan et al, 2010). Moreover, c-MYC and RHOA mRNA expression were negatively correlated in a cohort of 244 primary colorectal tumours (Supplementary Table 4).

We have previously shown that RHOA negatively regulates Wnt/c-MYC signalling in the colon cancer cells lines SW480/ADH, HCT8/S11, LS174T/W4 and SW837. To investigate the possible reciprocal regulation of the RHOA promoter by $\mathrm{c}-\mathrm{MYC}$ in colon cancer cells, we assessed the effects of ectopic expression of c-MYC in the same cell lines as well as in HEK293T human embryonic kidney cells. c-MYC can enhance the promoter activity of multiple targets, such as CDK4, through its binding to E-boxes or inhibit the promoter activity of other target genes, such as $p 21^{\text {CIPI/WAFI }}$ through alternative mechanisms (Seoane et al, 2002). As expected, overexpression of c-MYC led to a significant activation of the CDK4 promoter and reduced the activity of the $p 21^{C I P 1 / W A F 1}$ promoter (Figure 5A and B). In addition, and consistent with previous reports (Chan et al, 2010), c-MYC overexpression in HEK293T cells led to a significant increase in the transcription of RHOA (Figure 5C). However, ectopic expression of c-MYC in four different colon cancer cell lines (SW837, HCT8/S11, SW480/ADH and LS174T/W4) resulted in decreased RHOA promoter activity (Figure 5C).

To further confirm the regulation of $R H O A$ expression by c-MYC, we downregulated c-MYC levels either using c-MYCspecific shRNA (Figure $5 \mathrm{D}$ and $\mathrm{E}$ ) or treatment with the BET bromodomain inhibitor JQ1 (Figure 5F and G) that has previously been shown to reduce the expression of c-MYC (Delmore et al, 2011; Tögel et al, 2016). Transient shMYC transfection resulted in increased activity of the RHOA promoter in all four colon cancer cell lines (Figure 5E). In addition, JQ1 treatment led to increased mRNA and protein levels of RHOA as well as $p 21^{\text {CIP1/WAF1 that }}$ was used as a positive control (Cheng et al, 2013) (Figure 5F and $\mathrm{G})$. Collectively, these results demonstrate that c-MYC negatively regulates the activity of the promoter of RHOA and leads to reduced RHOA mRNA expression in colorectal cancer cells. 

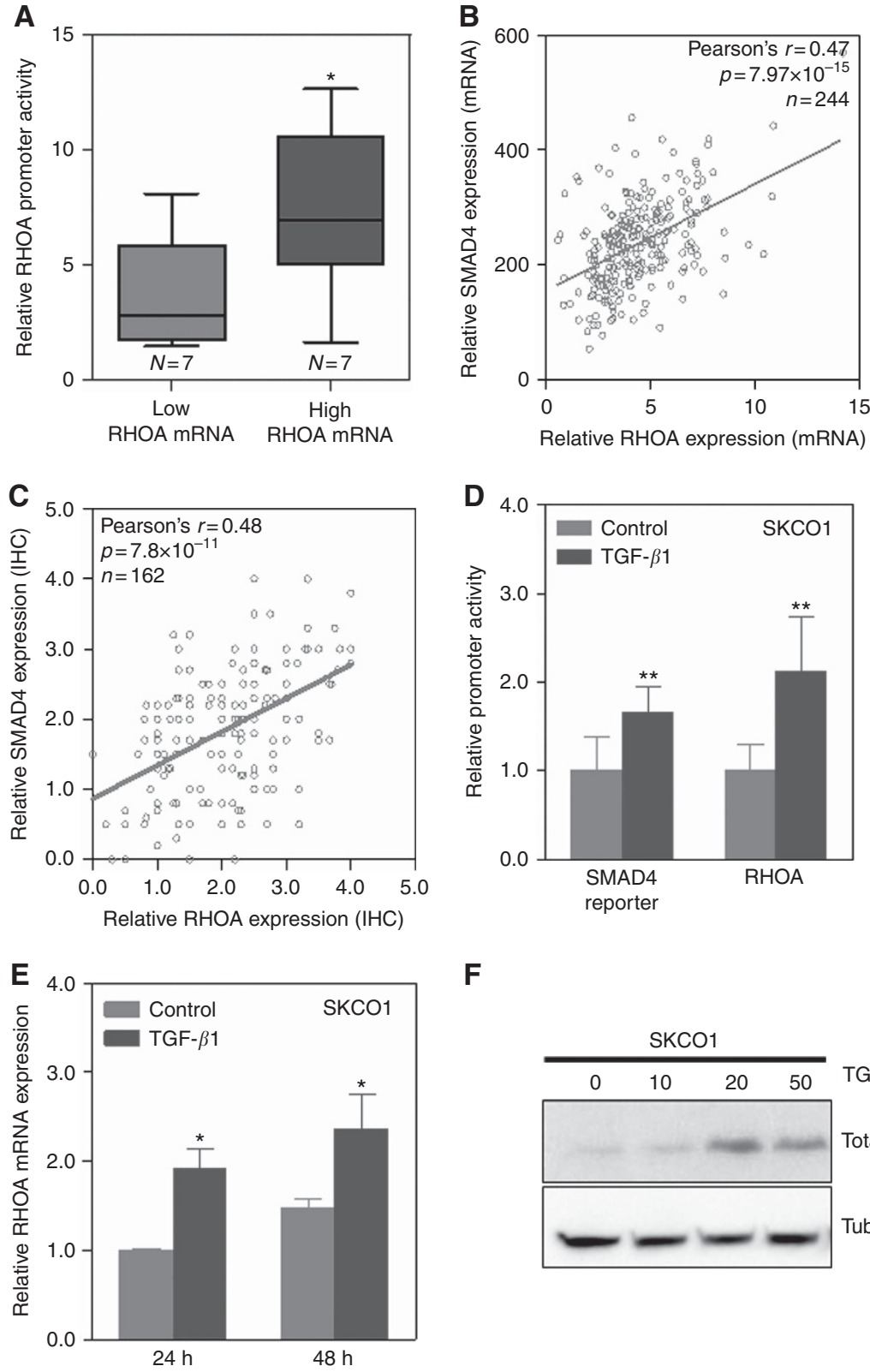

$\mathbf{F}$
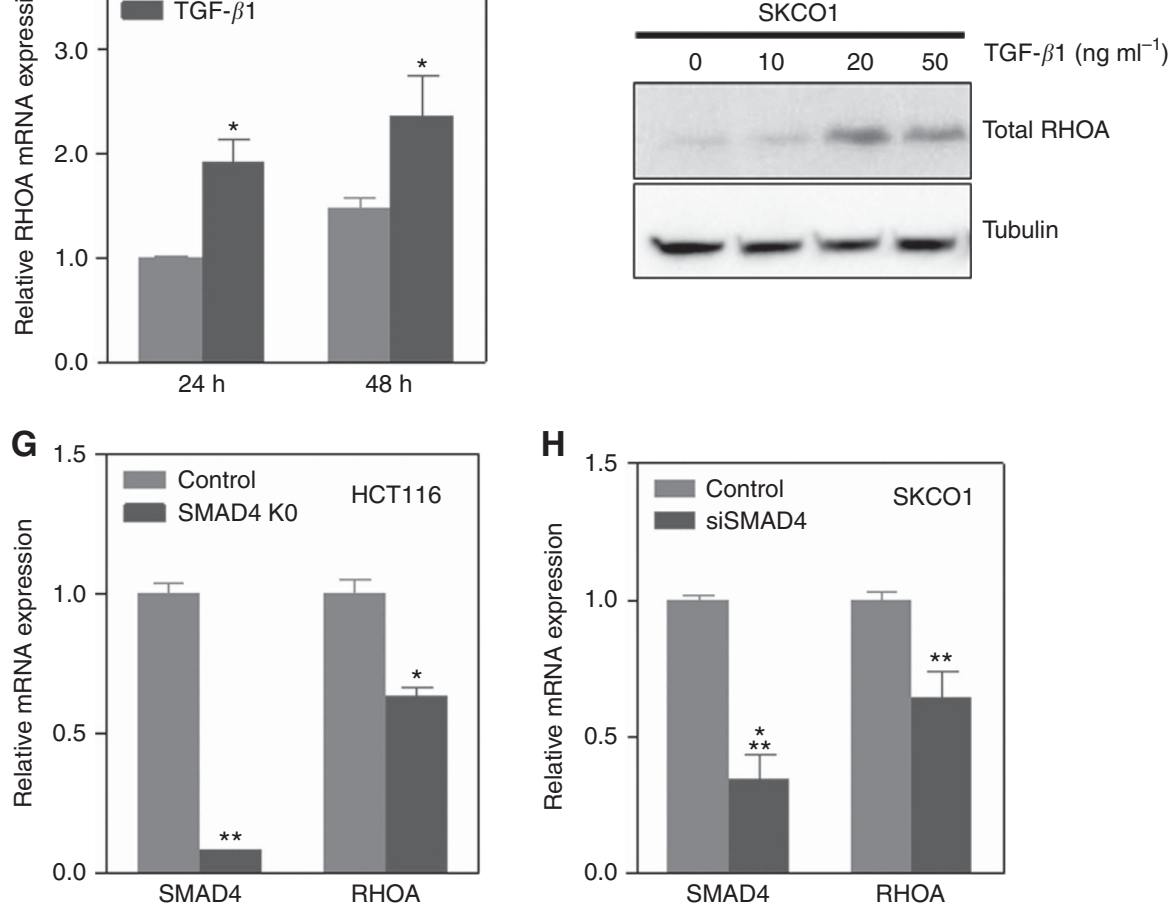

Figure 3. The RHOA regulation by TGF- $\beta /$ SMAD pathway. (A) Activity of the promoter of RHOA in 14 colorectal cancer cell lines with low and high RHOA expression. (B) Correlation between the expression of SMAD4 and RHOA mRNA levels (RNAseq) in 244 primary colorectal tumours (TCGA). (C) Correlation between the expression of SMAD4 and RHOA protein expression (immunohistochemistry) in a cohort of 162 primary Dukes' C colorectal tumours. (D-F) Changes in RHOA promoter activity (D) (luciferase reporter assay), RHOA mRNA expression (E) (qPCR) and RHOA protein expression (F) (western blotting) after treatment of SKCO1 colon cancer cells with TGF- $\beta 1$ for $24 \mathrm{~h}$ with the indicated concentrations. (G and $\mathbf{H})$ The SMAD4 and RHOA mRNA expression (qPCR) in HCT116 knockout cells compared with control HCT116 cells (G) and after SMAD4 downregulation in SKCO1 cells using siRNA $(\mathbf{H})$. The average ( \pm s.e.m.) of three independent experiments each run in triplicate is shown in $(\mathbf{A}, \mathbf{D}, \mathbf{E}, \mathbf{G}$ and $\mathbf{H})$. Student's t-test ${ }^{*} P<0.05 ;{ }^{\star \star} P<0.01 ;{ }^{* \star} P<0.001$. A full colour version of this figure is available at the British Journal of Cancer journal online. 
A
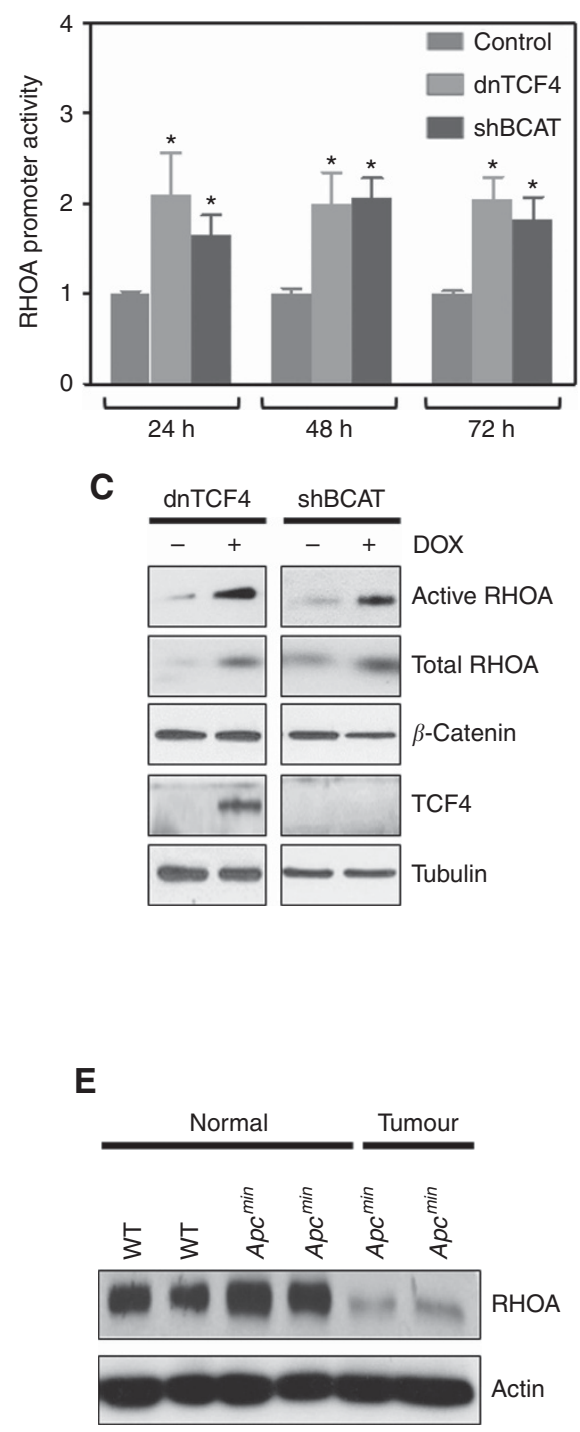

B

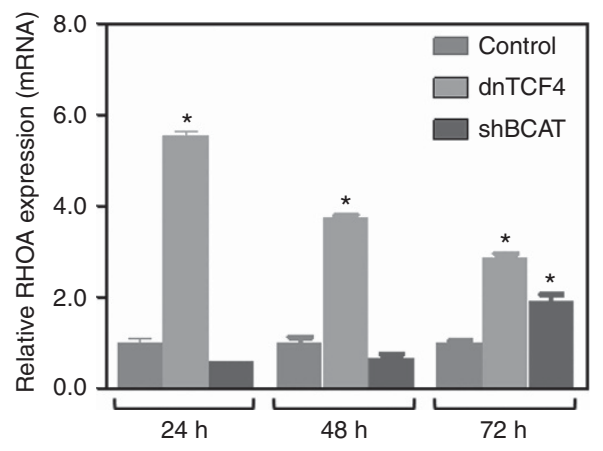

D
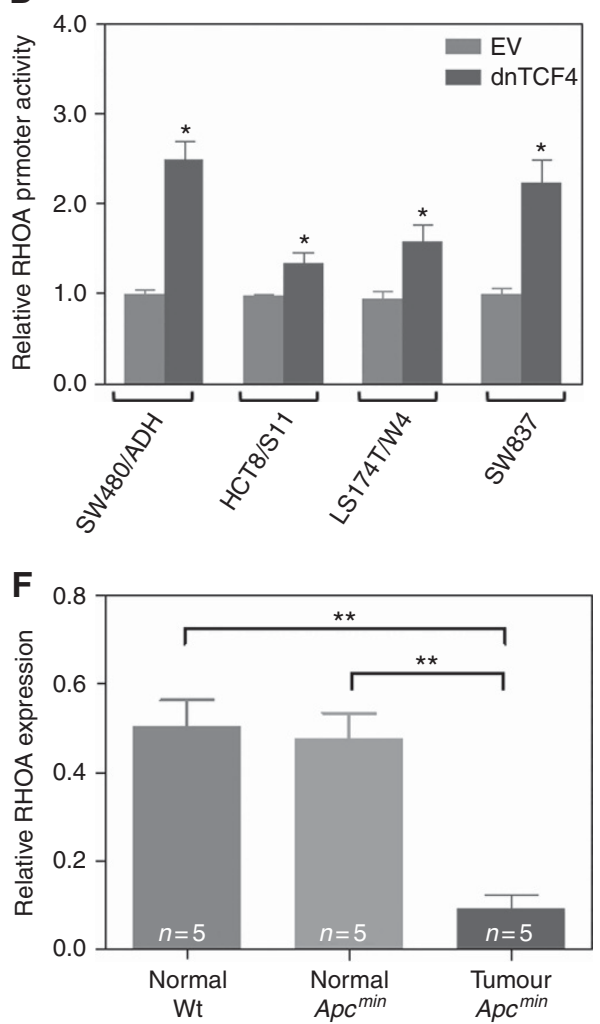

Figure 4. The RHOA regulation by Wnt signalling. (A) Changes in RHOA promoter activity after TCF4/ $\beta$-catenin inactivation following doxycycline exposure in LS174T/dnTCF4 and LS174T/shBCAT cells. (B) Expression of RHOA (qPCR) in LS174T/dnTCF4 and LS174T/shBCAT cells after TCF4/ $\beta$-catenin inactivation. (C) Total and active RHOA in LS174T/dnTCF4 and LS174T/shBCAT cells after TCF4/ $\beta$-catenin inactivation. The levels of TCF4, $\beta$-catenin and tubulin are also shown. (D) Changes in RHOA promoter activity in SW480/ADH, HCT8/S11, LS174T/W4 and SW837 colon cancer cells with transient overexpression of dnTCF4. (E) Western blot showing the relative expression of RhoA in the normal intestinal epithelial cells of control wild-type mice (WT), in the normal intestinal epithelial cells of $A p c^{\min }$ mice and in the intestinal tumours of Apc ${ }^{\mathrm{min}}$ animals. Actin was used as a loading control. (F) Histogram showing the average ( \pm s.e.m.) RhoA protein expression quantified from five different animals. The average ( \pm s.e.m.) of three independent experiments each run in triplicate is shown in (A, B and $\mathbf{D})$. Student's t-test ${ }^{\star} P<0.05$; ${ }^{\star \star} P<0.01$. A full colour version of this figure is available at the British Journal of Cancer journal online.

c-MYC represses the $R H O A$ promoter through its interactions with SP1. c-MYC has been shown to repress the promoter activity of target genes such as $U S F, C / E B P \alpha$ or albumin through its binding to initiator elements (Li et al, 1994). However, detailed in silico analysis of the RHOA promoter did not identify the presence of any consensus initiator elements. Alternatively, c-MYC can repress the expression of some genes, such as $p 21^{C I P 1 / W A F 1}$, through the sequestration of the SP1/SP3 complex (Gartel et al, 2001). Similar to the $p 21^{\text {CIPI/WAF1 }}$ promoter, the proximal promoter of RHOA contains several SP1 binding sites (Figure 6A), and the levels of SP1 were significantly correlated with the expression of RHOA in a series of 244 primary colorectal tumours (Supplementary Tables 2 and 4; Pearson's $\left.r=0.37 ; \quad P=5.8 \times 10^{-9}\right) . \quad$ A chromatin immunoprecipitation (ChIP) assay demonstrated a significant enrichment in SP1-bound DNA fragments spanning the RHOA promoter region in untreated colon cancer cells compared with negative controls (compare blue bars with (DMSO IgG) and without (DMSO SP1) stripes for the RHOA promoter in Figure 6D), demonstrating SP1 binding to the RHOA promoter and further suggesting that SP1 is important for RHOA transcription. Treatment with the SP1 inhibitor mithramycin resulted in a significant reduction of the promoter activity and the expression of $R H O A$, as well as the positive control $p 21^{C I P 1 / W A F 1}$ (Figure $6 \mathrm{~B}$ and $\mathrm{C}$ ), further indicating that SP1 transactivation is important to sustain RHOA expression in colon cancer cells. 

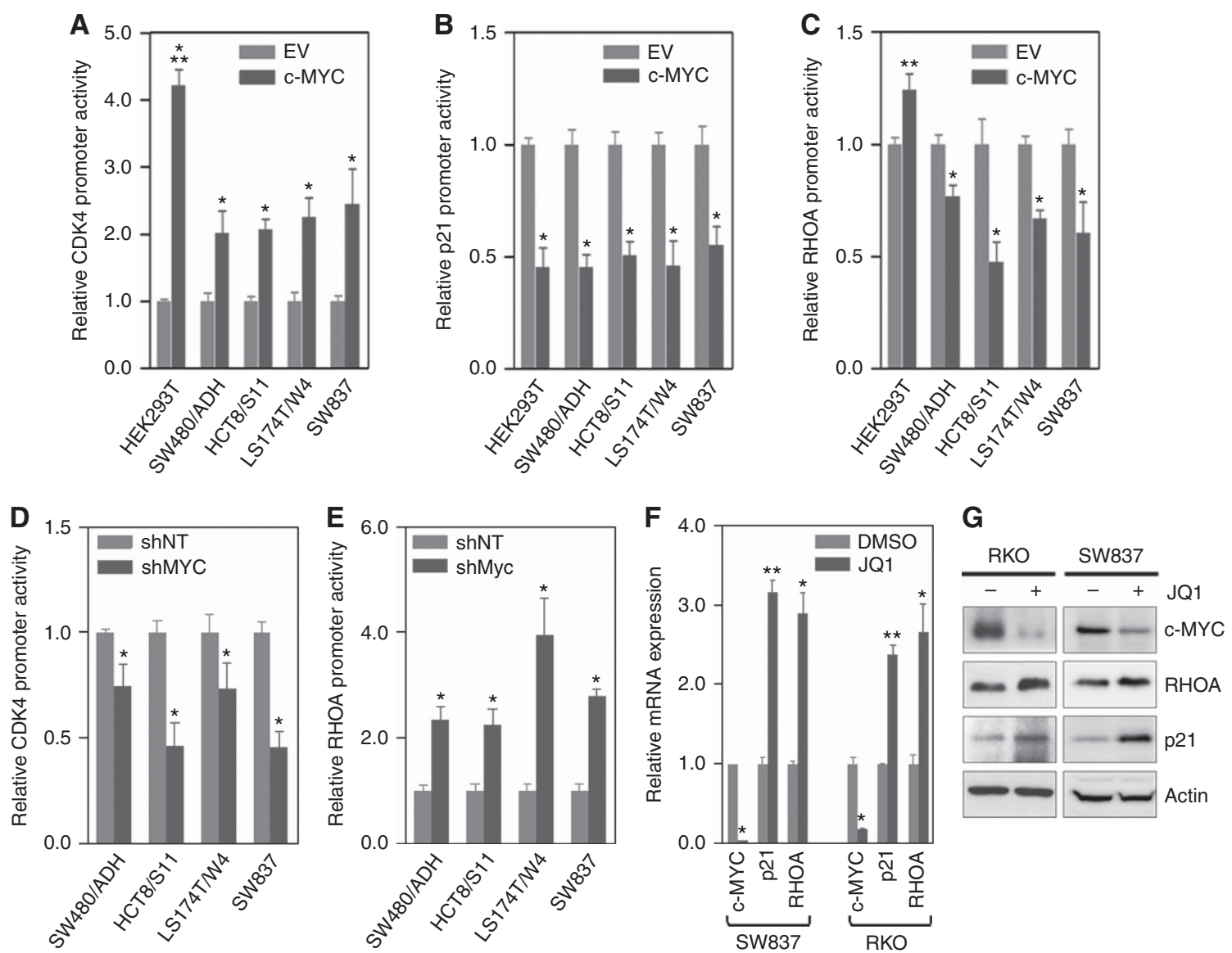

Figure 5. The RHOA regulation by c-MYC. (A) CDK4, (B) p21CIP1/WAF1 and (C) RHOA promoter activity in SW480/ADH, HCT/S11, LS174T/W4 and SW837 colon cancer cells and kidney embryonic HEK293T cells with transient overexpression of c-MYC or the empty vector (EV) control construct. (D) CDK4 and (E) RHOA promoter activity in response to c-MYC downregulation by a specific shRNA or a non-targeting (NT) control shRNA. (F) Relative mRNA expression of c-MYC, p21 CIP1 WAF1 and RHOA in SW837 and RKO colon cancer cells after JQ1 treatment for $24 \mathrm{~h}$. (G) Western blot analysis showing the relative levels of c-MYC, p $21^{\text {CIP1 } 1 \text { WAF1 }}$ and RHOA in RKO and SW837 cells after JQ1 treatment. Actin was used as a loading control. The average ( \pm s.e.m.) of three independent experiments each run in triplicate is shown for $(\mathbf{A}-\mathbf{F})$. Student's $t$-test ${ }^{*} P<0.05$; ${ }^{\star \star} P<0.01 ;{ }^{\star \star \star} P<0.001$. A full colour version of this figure is available at the British Journal of Cancer journal online.

To investigate whether c-MYC downregulates the expression of RHOA by interfering with the capacity of SP1 to activate RHOA transcription, we assessed possible changes in the levels of SP1 bound to the RHOA promoter following c-MYC downregulation with JQ1. As a control (Gartel et al, 2001), we showed increased SP1 binding to the $p 21^{C I P 1 / W A F 1}$ promoter after c-MYC downregulation with JQ1 treatment using a ChIP assay (compare blue (DMSO SP1) and green (JQ1 SP1) bars without stripes for the p21 promoter in Figure 6D). Importantly, reduced c-MYC levels after JQ1 treatment resulted in a significant increase in SP1 bound to the RHOA promoter (compare blue (DMSO SP1) and green (JQ1 SP1) bars without stripes for the RHOA promoter in Figure 6D), consistent with the notion that c-MYC downregulates RHOA levels in colon cancer cells by reducing SP1 binding to the RHOA proximal promoter.

\section{DISCUSSION}

RHOA is a small GTPase that in normal epithelial cells functions as an important regulator of cytoskeleton structure, differentiation, polarisation, cell adhesion and motility, and is activated in most tumour types where it has been studied, mostly through its overexpression (Itoh et al, 1999; Sahai and Marshall, 2002). In contrast, we have previously shown that RHOA expression is frequently lost or reduced in colorectal tumours and that low levels of expression are associated with poor patient prognosis (Arango et al, 2005), probably because of context-dependent differences in RHOA signalling. Moreover, we have recently reported that the loss of RHOA is an important driver of colorectal cancer progression and metastasis (Rodrigues et al, 2014). However, the underlying molecular mechanisms responsible for RHOA inactivation in colorectal tumours have not been previously investigated. Here, we have carried out a comprehensive analysis of the possible mechanisms downregulating RHOA activity in colorectal tumours, and found that RHOA signalling is regulated by multiple mechanisms that result in a significant reduction of RHOA expression and activity in a high proportion of these tumours.

The RHO GTPases function as molecular switches that cycle between a GTP-bound active state and a GDP-bound inactive state. Here we found that although the levels of active RHOA-GTP are known to be regulated by GEF and GAP proteins (Sahai and Marshall, 2002), in colon cancer cells, the promoter activity as well as the levels of RHOA mRNA and protein are significantly correlated with the levels of GTP-bound active RHOA, as determined by a pulldown assay based on the Rho binding domain (RBD) of the Rho effector Rhotekin. These data indicate that RHOA signalling is determined to a large extent by the transcriptional activity of the RHOA promoter, although other layers of regulation further finetune RHOA activity on colorectal tumours.

Whereas frequent recurrent RHOA mutations have been reported in subtypes of $\mathrm{T}$-cell leukaemia/lymphoma (Palomero 
A

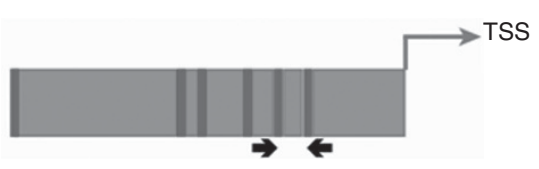

RHOA promoter

B

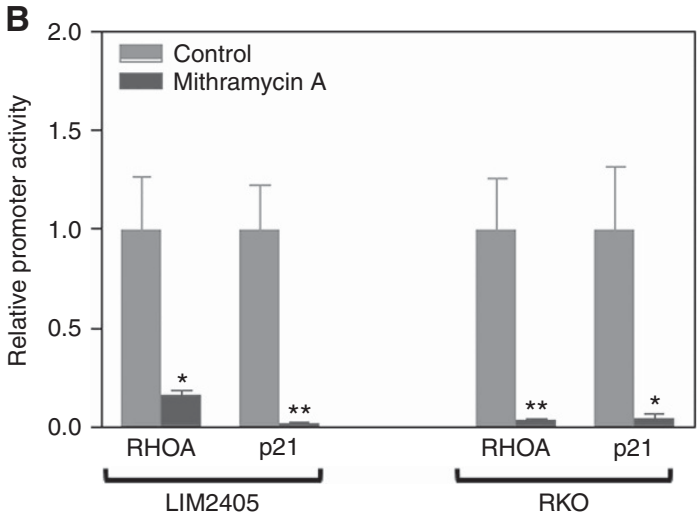

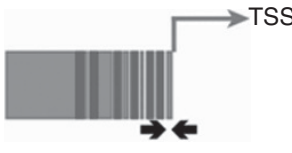

p21 promoter

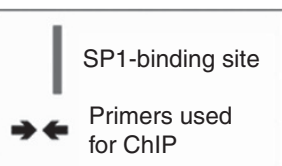

C

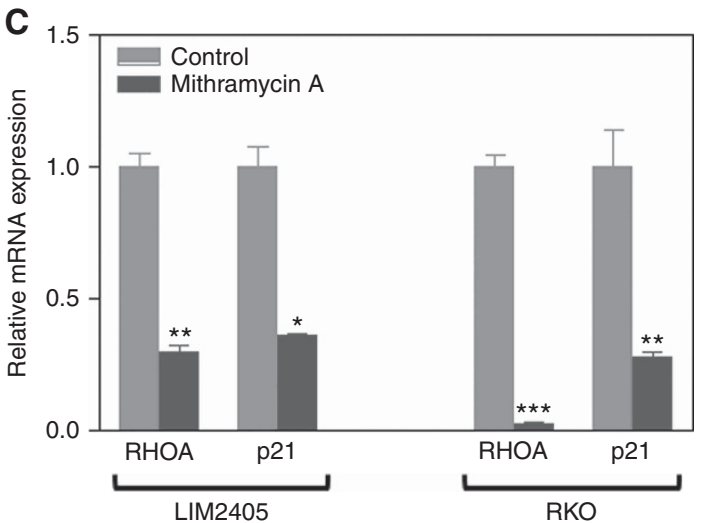

D

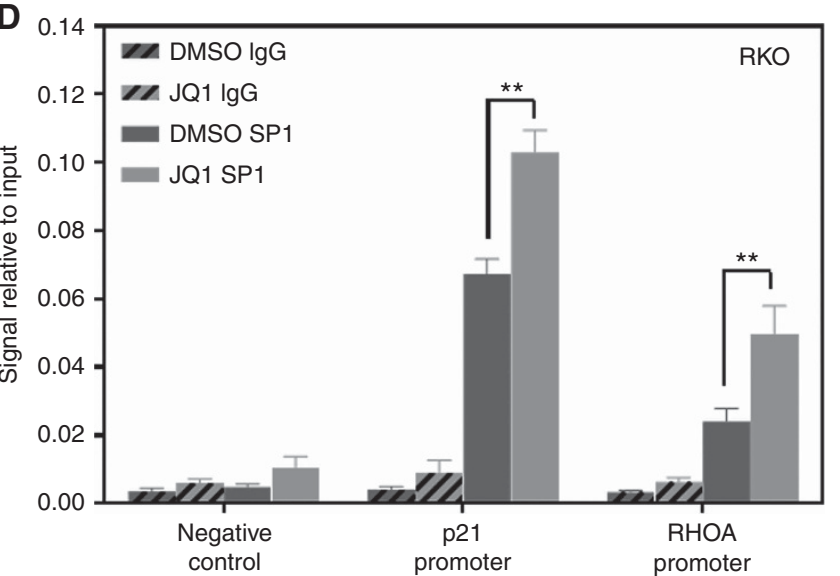

Figure 6. The c-MYC regulates RHOA levels through SP1. (A) Schematic representation of the RHOA and p21CIP1/WAF1 promoters showing the localisation of SP1-binding sites and the primers used for QPCR after chromatin immunoprecipitation with an anti-SP1 antibody. (B and C) Effects of Mithramycin A treatment on the promoter activity (B) and the mRNA expression (C) of RHOA and p21 CIP1/WAF1. (D) Results of a ChIP assay showing relative levels of SP1 bound to the RHOA promoter in RKO cells after treatment with JQ1 or control vehicle (DMSO). p21 CIP1/WAF1 was used as a SP1-binding positive control and gene desert in chromosome 12 (chr12:61 667 747-61 667 824) as negative control. Nonspecific polyclonal IgG was used as a negative control for the ChIP assay. The average ( \pm s.e.m.) of three independent experiments run in triplicate is shown for (B-D). Student's t-test ${ }^{\star} P<0.05 ;{ }^{\star \star} P<0.01 ;{ }^{* \star} P<0.001$. A full colour version of this figure is available at the British Journal of Cancer journal online.

et al, 2014) and gastric tumours (Zhou et al, 2014), RHOA mutations are not frequent $(1.0 \% ; 10$ out of 983$)$ in colorectal tumours, indicating that this is not a common mechanism regulating $\mathrm{RHOA}$ signalling in this tumour type. However, $\mathrm{RHOA}$ is located on the short arm of chromosome 3 (3p21.3), a region frequently deleted in colorectal tumours (Mehus et al, 1999) and that is known to contain several candidate tumour suppressor genes, including NPRL2 (Yogurtcu et al, 2012) and RASSF1 (Fernandes et al, 2013). Here we show that copy number losses in 3 p21.3 are associated with a significant reduction in $R H O A$ expression, suggesting that these deletions could target $R H O A$ among other genes in this region.

We show here that despite the presence of a dense CpG island in the promoter of $R H O A$, uniformly low levels of methylation were observed in this region in primary colorectal tumours and cell lines, and no associations were observed with RHOA mRNA expression, indicating that aberrant promoter hypermethylation does not significantly contribute to RHOA silencing in colorectal cancer. Interestingly, the transcription start site (TSS) of RHOA is located only three base pairs away from the TSS of TCTA (T-cell leukaemia translocation altered), a gene that is transcribed in the opposite direction. The TSSs of both RHOA and TCTA are contained within the $\mathrm{CpG}$ island investigated here and likely contribute to the regulation of the expression of both genes. As previous studies have shown that TCTA may have an oncogenic function, this could explain the absence of methylation in this CpG island spanning the TSS of RHOA and TCTA, even in tumours with $\mathrm{CpG}$ island methylator phenotype (CIMP).

Using genome-wide transcriptomic analysis of both mRNA and miRNA, we identified 12 miRNAs whose expression shows a significant negative correlation with RHOA mRNA levels, have putative binding sites in the $3^{\prime}$-UTR of RHOA and are significantly overexpressed in colorectal tumours compared with the normal colonic mucosa. As expected, some of these miRNAs, including miR-183 (Bi et al, 2016), miR-20a (Cheng et al, 2016) and miR-185 (Liu et al, 2011), have previously been shown to directly regulate RHOA levels and/or to be involved in colorectal carcinogenesis. Here, we further investigated the possible role of $m i R-200 a / b / 429$ on the regulation of RHOA expression in colorectal cancer 
cells. The $m i R-200$ family is located in two genomic clusters, $m i R$ $200 a / b / 429$ on chromosome 1 and miR200c/141 on chromosome 12 . We found that $m i R-200 a / b / 429$ overexpression significantly reduced the levels of RHOA expression in LIM2405 colon cancer cells. These results are in good agreement with a recent report where miR-200b was found to reduce RHOA expression in hepatocellular cells (Wong et al, 2015).

Although the function of a protein can be post-transcriptionally modulated, transcriptional control at the promoter level represents a major mechanism of gene expression regulation. Here, we identified a set of 44 transcription factors with evolutionary conserved binding sites in the promoter of $R H O A$, whose expression is significantly correlated with $R H O A$ expression in a cohort of 244 colorectal tumours, suggesting that they may be important for the transcriptional regulation of $R H O A$. Two of these transcription factors, SMAD4 and c-MYC, are key regulators of the two most frequently deregulated signalling pathways in colorectal tumours, TGF- $\beta$ and Wnt respectively, and we demonstrate here that they are important for the regulation of RHOA levels in colon cancer cells.

Inactivation of the TGF- $\beta$ signalling pathway is important for colorectal cancer progression, as illustrated by the frequent alterations observed in TGF- $\beta$ receptors (Parsons et al, 1995) or the SMAD intracellular mediators such as SMAD4 inactivation (Alazzouzi et al, 2005). Although TGF- $\beta$ signalling has been shown to activate RHOA in a SMAD-independent manner (Moustakas et al, 2001), we show here that SMAD4 inactivation leads to a 30 $40 \%$ reduction of the levels of RHOA in colon cancer cells, suggesting that RHOA activation may significantly contribute to TGF- $\beta$-mediated tumour suppression in colonic epithelial cells, although the specific RHOA-dependent mechanisms remain to be elucidated. Wnt signalling is a master regulator of proliferation and differentiation of the normal intestinal epithelium and colon cancer cells (MacDonald et al, 2009). Aberrant activation of Wnt signalling in colorectal tumours leads to the accumulation of nuclear $\beta$-catenin that binds to the transcription factor TCF4, driving the expression of multiple $\beta$-catenin/TCF4 target genes, and c-MYC has been shown to be an important determinant of the oncogenic effects of Wnt hyperactivation in colorectal tumours (Sansom et al, 2007). c-MYC positively regulates the expression of RHOA in glioblastoma, prostate and breast cancer cells as well as kidney embryonic cells through the direct binding to E-boxes in the RHOA promoter (Seoane et al, 2002; Si et al, 2010; Talamillo et al, 2017). Surprisingly, however, we found that in colon cancer cells SP1 is required for active transcription of RHOA, and that c-MYC interferes with the binding of SP1 to the RHOA promoter, thus downregulating RHOA expression, as previously shown for the CDK inhibitor $p 21^{C I P 1 / W A F 1}$ (Gartel et al, 2001). Therefore, as we have recently shown that the loss of RHOA enhances Wnt signalling and significantly contributes to colon cancer progression and metastasis (Rodrigues et al, 2014), we describe here the existence of a positive cross-regulatory feedback loop, where reduced RHOA leads to enhanced Wnt/MYC signalling that in turn further reduces $R H O A$ levels. Importantly, these data illustrate how the same transcription factor can regulate in opposite directions the transcription of the same gene in two different cancer cell types, highlighting the complexity of gene expression regulation in the human genome.

In conclusion, we demonstrate a complex pattern of inactivation of $R H O A$ in colon cancer cells involving overlapping genetic, transcriptional and post-transcriptional mechanisms in colon cancer cells. Deletions affecting $R H O A$ are associated with reduced $R H O A$ expression and $m i R-200 a / b / 429$ regulates the expression of this GTPase in colorectal cancer cells. In addition, we demonstrate that RHOA is regulated by the transcription factors SMAD4 and c-MYC, key mediators of the most commonly deregulated signalling pathways on colorectal cancer, TGF- $\beta$ and Wnt respectively.

\section{ACKNOWLEDGEMENTS}

This study was partially funded by grants of the Association for International Cancer Research (AICR13-0245), the Spanish Ministry for Economy and Competitiveness (CP05/00256, PI12/ 03103, PI12/01095, PI16/00540 and AC15/00066) and Asociación Española contra el Cáncer (AECC GCA15152966ARAN) to Diego Arango. Higinio Dopeso is supported by a Juan de la Cierva fellowship (JCI-2012-14357).

\section{CONFLICT OF INTEREST}

The authors declare no conflict of interest.

\section{REFERENCES}

Alazzouzi H, Alhopuro P, Salovaara R, Sammalkorpi H, Järvinen H, Mecklin J-P, Hemminki A, Schwartz S, Aaltonen LA, Arango D (2005) SMAD4 as a prognostic marker in colorectal cancer. Clin Cancer Res 11: 2606-2611.

Alhopuro P, Alazzouzi H, Sammalkorpi H, Dávalos V, Salovaara R, Hemminki A, Järvinen H, Mecklin J-P, Schwartz S, Aaltonen LA, Arango D (2005) SMAD4 levels and response to 5-fluorouracil in colorectal cancer. Clin Cancer Res 11: 6311-6316.

Arango D, Laiho P, Kokko A, Alhopuro P, Sammalkorpi H, Salovaara R, Nicorici D, Hautaniemi S, Alazzouzi H, Mecklin J-P, Järvinen H, Hemminki A, Astola J, Schwartz S, Aaltonen LA (2005) Gene-expression profiling predicts recurrence in Dukes' C colorectal cancer. Gastroenterology 129: 874-884.

Bazzocco S, Dopeso H, Carton-Garcia F, Macaya I, Andretta E, Chionh F, Rodrigues P, Garrido M, Alazzouzi H, Nieto R, Sanchez A, Schwartz S, Bilic J, Mariadason JM, Arango D (2015) highly expressed genes in rapidly proliferating tumor cells as new targets for colorectal cancer treatment. Clin Cancer Res 21: 3695-3704.

Betel D, Koppal A, Agius P, Sander C, Leslie C (2010) Comprehensive modeling of microRNA targets predicts functional non-conserved and non-canonical sites. Genome Biol 11: R90.

Bi DP, Yin CH, Zhang XY, Yang NN, Xu JY (2016) MIR-183 functions as an oncogene by targeting ABCA1 in colon cancer. Oncol Rep 35: 2873-2879.

Bienz M, Clevers H (2000) Linking colorectal cancer to Wnt signaling. Cell 103: $311-320$

Bijkerk R, de Bruin RG, van Solingen C, Duijs JMGJ, Kobayashi K, van der Veer EP, ten Dijke P, Rabelink TJ, Goumans MJ, van Zonneveld AJ (2012) MicroRNA-155 functions as a negative regulator of RhoA signaling in TGF-beta-induced endothelial to mesenchymal transition. MicroRNA 1: $2-10$.

Braga EA, Loginov VI, Pronina I V, Khodyrev DS, Rykov S V, Burdennyy AM, Friedman M V, Kazubskaya TP, Kubatiev AA, Kushlinskii NE (2015) Upregulation of RHOA and NKIRAS1 genes in lung tumors is associated with loss of their methylation as well as with methylation of regulatory miRNA genes. Biochem 80: 483-494.

Brannon A, Vakiani E, Sylvester BE, Scott SN, McDermott G, Shah RH, Kania K, Viale A, Oschwald DM, Vacic V, Emde A-K, Cercek A, Yaeger R, Kemeny NE, Saltz LB, Shia J, D Angelica MI, Weiser MR, Solit DB, Berger MF, D’Angelica MI (2014) Comparative sequencing analysis reveals high genomic concordance between matched primary and metastatic colorectal cancer lesions. Genome Biol 15: 454.

Brunen D, Willems SM, Kellner U, Midgley R, Simon I, Bernards R (2013) TGF- $\beta$ : an emerging player in drug resistance. Cell Cycle 12: 2960-2968. Cancer Genome Atlas Network (2012) Comprehensive molecular characterization of human colon and rectal cancer. Nature 487: 330-337. Chan C-H, Lee S-W, Li C-F, Wang J, Yang W-L, Wu C-Y, Wu J, Nakayama KI, Kang H-Y, Huang H-Y, Hung M-C, Pandolfi PP, Lin H-K (2010) Deciphering the transcriptional complex critical for RhoA gene expression and cancer metastasis. Nat Cell Biol 12: 457-467.

Cheng D, Zhao S, Tang H, Zhang D, Sun H, Yu F, Jiang W, Yue B, Wang J, Zhang M, Yu Y, Liu X, Sun X, Zhou Z, Qin X, Zhang X, Yan D, Wen Y, Peng Z (2016) MicroRNA-20a-5p promotes colorectal cancer invasion and metastasis by downregulating Smad4. Oncotarget 7(29): 45199-45213. 
Cheng Z, Gong Y, Ma Y, Lu K, Lu X, Pierce LA, Thompson RC, Muller S, Knapp S, Wang J (2013) Inhibition of BET bromodomain targets genetically diverse glioblastoma. Clin Cancer Res 19: 1748-1759.

Corté H, Manceau G, Blons H, Laurent-Puig P (2012) MicroRNA and colorectal cancer. Dig Liver Dis 44: 195-200.

Delmore JE, Issa GC, Lemieux ME, Rahl PB, Shi J, Jacobs HM, Kastritis E, Gilpatrick T, Paranal RM, Qi J, Chesi M, Schinzel AC, McKeown MR, Heffernan TP, Vakoc CR, Bergsagel PL, Ghobrial IM, Richardson PG, Young RA, Hahn WC, Anderson KC, Kung AL, Bradner JE, Mitsiades CS (2011) BET bromodomain inhibition as a therapeutic strategy to target c-Myc. Cell 146: 904-917.

Eppert K, Scherer SW, Ozcelik H, Pirone R, Hoodless P, Kim H, Tsui LC, Bapat B, Gallinger S, Andrulis IL, Thomsen GH, Wrana JL, Attisano L (1996) MADR2 maps to 18q21 and encodes a TGFbeta-regulated MAD-related protein that is functionally mutated in colorectal carcinoma. Cell 86: 543-552.

Fernandes MS, Carneiro F, Oliveira C, Seruca R (2013) Colorectal cancer and RASSF family-a special emphasis on RASSF1A. Int J Cancer 132: 251-258.

Gartel AL, Ye X, Goufman E, Shianov P, Hay N, Najmabadi F, Tyner AL (2001) Myc represses the p21(WAF1/CIP1) promoter and interacts with Sp1/Sp3. Proc Natl Acad Sci USA 98: 4510-4515.

Giannakis M, Mu XJ, Shukla SA, Qian ZR, Cohen O, Nishihara R, Bahl S, Cao Y, Amin-Mansour A, Yamauchi M, Sukawa Y, Stewart C, Rosenberg M, Mima K, Inamura K, Nosho K, Nowak JA, Lawrence MS, Giovannucci EL, Chan AT, Ng K, Meyerhardt JA, Van Allen EM, Getz G, Gabriel SB, Lander ES, Wu CJ, Fuchs CS, Ogino S, Garraway LA (2016) Genomic correlates of immune-cell infiltrates in colorectal carcinoma. Cell Rep 15: 857-865.

Howe JR, Roth S, Ringold JC, Summers RW, Järvinen HJ, Sistonen P, Tomlinson IP, Houlston RS, Bevan S, Mitros FA, Stone EM, Aaltonen LA (1998) Mutations in the SMAD4/DPC4 gene in juvenile polyposis. Science 280: 1086-1088.

Hur K, Toiyama Y, Takahashi M, Balaguer F, Nagasaka T, Koike J, Hemmi H, Koi M, Boland CR, Goel A (2013) MicroRNA-200c modulates epithelialto-mesenchymal transition (EMT) in human colorectal cancer metastasis. Gut 62: 1315-1326.

Itoh K, Yoshioka K, Akedo H, Uehata M, Ishizaki T, Narumiya S (1999) An essential part for Rho-associated kinase in the transcellular invasion of tumor cells. Nat Med 5: 221-225.

Jian Q, An Q, Zhu D, Hui K, Liu Y, Chi S, Li C (2014) MicroRNA 340 is involved in UVB-induced dendrite formation through the regulation of RhoA expression in melanocytes. Mol Cell Biol 34: 3407-3420.

Li LH, Nerlov C, Prendergast G, MacGregor D, Ziff EB (1994) c-Myc represses transcription in vivo by a novel mechanism dependent on the initiator element and Myc box II. EMBO J 13: 4070-4079.

Liu M, Lang N, Chen X, Tang Q, Liu S, Huang J, Zheng Y, Bi F (2011) MiR185 targets RhoA and Cdc42 expression and inhibits the proliferation potential of human colorectal cells. Cancer Lett 301: 151-160.

Luongo C, Moser AR, Gledhill S, Dove WF (1994) Loss of Apc + in intestinal adenomas from min mice. Cancer Res 54: 5947-5952.

MacDonald BT, Tamai K, He X (2009) Wnt/beta-catenin signaling: components, mechanisms, and diseases. Dev Cell 17: 9-26.

Mehus JG, Deloukas P, Lambeth DO (1999) NME6: a new member of the $\mathrm{nm} 23 /$ nucleoside diphosphate kinase gene family located on human chromosome 3p21.3. Hum Genet 104: 454-459.

Mishra L, Shetty K, Tang Y, Stuart A, Byers SW (2005) The role of TGF-beta and Wnt signaling in gastrointestinal stem cells and cancer. Oncogene 24: 5775-5789.

Moser AR, Pitot HC, Dove WF (1990) A dominant mutation that predisposes to multiple intestinal neoplasia in the mouse. Science 247: 322-324.

Mouradov D, Sloggett C, Jorissen RN, Love CG, Li S, Burgess AW, Arango D, Strausberg RL, Buchanan D, Wormald S, O'Connor L, Wilding JL, Bicknell D, Tomlinson IPM, Bodmer WF, Mariadason JM, Sieber OM (2014) Colorectal cancer cell lines are representative models of the main molecular subtypes of primary cancer. Cancer Res 74: 3238-3247.

Moustakas A, Souchelnytskyi S, Heldin C-H (2001) Smad regulation in TGF- $\beta$ signal transduction. J Cell Sci 114: 4359-4369.

Palomero T, Couronne L, Khiabanian H, Kim MY, Ambesi-Impiombato A, Perez-Garcia A, Carpenter Z, Abate F, Allegretta M, Haydu JE, Jiang X, Lossos IS, Nicolas C, Balbin M, Bastard C, Bhagat G, Piris MA, Campo E, Bernard OA, Rabadan R, Ferrando AA (2014) Recurrent mutations in epigenetic regulators, RHOA and FYN kinase in peripheral T cell lymphomas. Nat Genet 46: 166-170.

Parsons R, Myeroff LL, Liu B, Willson JK, Markowitz SD, Kinzler KW, Vogelstein B (1995) Microsatellite instability and mutations of the transforming growth factor beta type II receptor gene in colorectal cancer. Cancer Res 55: 5548-5550.

Rodrigues P, Macaya I, Bazzocco S, Mazzolini R, Andretta E, Dopeso H, Mateo-Lozano S, Bilić J, Cartón-García F, Nieto R, Suárez-López L, Afonso E, Landolfi S, Hernandez-Losa J, Kobayashi K, Ramón y, Cajal S, Tabernero J, Tebbutt NC, Mariadason JM, Schwartz S, Arango D (2014) RHOA inactivation enhances Wnt signalling and promotes colorectal cancer. Nat Commun 5: 5458.

Sahai E, Marshall CJ (2002) RHO-GTPases and cancer. Nat Rev Cancer 2: 133-142.

Sansom OJ, Meniel VS, Muncan V, Phesse TJ, Wilkins JA, Reed KR, Vass JK, Athineos D, Clevers H, Clarke AR (2007) Myc deletion rescues Apc deficiency in the small intestine. Nature 446: 676-679.

Sansom OJ, Reed KR, Hayes AJ, Ireland H, Brinkmann H, Newton IP, Batlle E, Simon-Assmann P, Clevers H, Nathke IS, Clarke AR, Winton DJ (2004) Loss of Apc in vivo immediately perturbs Wnt signaling, differentiation, and migration. Genes Dev 18: 1385-1390.

Seoane J, Le H-V, Massagué J (2002) Myc suppression of the p21(Cip1) Cdk inhibitor influences the outcome of the p53 response to DNA damage. Nature 419: 729-734.

Seshagiri S, Stawiski EW, Durinck S, Modrusan Z, Storm EE, Conboy CB, Chaudhuri S, Guan Y, Janakiraman V, Jaiswal BS, Guillory J, Ha C, Dijkgraaf GJP, Stinson J, Gnad F, Huntley M a, Degenhardt JD, Haverty PM, Bourgon R, Wang W, Koeppen H, Gentleman R, Starr TK, Zhang Z, Largaespada DA, Wu TD, de Sauvage FJ (2012) Recurrent R-spondin fusions in colon cancer. Nature 488: 660-664.

Si J, Yu X, Zhang Y, DeWille JW (2010) Myc interacts with Max and Miz1 to repress C/EBPdelta promoter activity and gene expression. Mol Cancer 9: 92.

Talamillo A, Grande L, Ruiz-Ontañon P, Velasquez C, Mollinedo P, Torices S, Sanchez-Gomez P, Aznar A, Esparis-Ogando A, Lopez-Lopez C, Lafita C, Berciano MT, Montero JA, Vazquez-Barquero A, Segura V, Villagra NT, Pandiella A, Lafarga M, Leon J, Martinez-Climent JA, Sanz-Moreno V, Fernandez-Luna JL (2017) ODZ1 allows glioblastoma to sustain invasiveness through a Myc-dependent transcriptional upregulation of RhoA. Oncogene 36: 1733-1744.

Tögel L, Nightingale R, Chueh AC, Jayachandran A, Tran H, Phesse T, Wu R, Sieber OM, Arango D, Dhillon AS, Dawson MA, Diez-Dacal B, Gahman TC, Filippakopoulos P, Shiau AK, Mariadason JM (2016) Dual targeting of bromodomain and extraterminal domain proteins, and WNT or MAPK signaling, inhibits c-MYC expression and proliferation of colorectal cancer cells. Mol Cancer Ther 15: 1217-1226.

Tsankov AM, Gu H, Akopian V, Ziller MJ, Donaghey J, Amit I, Gnirke A, Meissner A (2015) Transcription factor binding dynamics during human ES cell differentiation. Nature 518: 344-349.

Van de Wetering M, Sancho E, Verweij C, De Lau W, Oving I, Hurlstone A, Van der Horn K, Batlle E, Coudreuse D, Haramis AP, Tjon-Pon-Fong M, Moerer P, Van den Born M, Soete G, Pals S, Eilers M, Medema R, Clevers H (2002) The B-catenin/TCF-4 complex imposes a crypt progenitor phenotype on colorectal cancer cells. Cell 111: 241-250.

Wong C-M, Wei L, Au SL-K, Fan DN-Y, Zhou Y, Tsang FH-C, Law C-T, Lee JM-F, He X, Shi J, Wong CC-L, Ng IO-L (2015) MiR-200b/200c/429 subfamily negatively regulates Rho/ROCK signaling pathway to suppress hepatocellular carcinoma metastasis. Oncotarget 6: 13658-13670.

Yogurtcu B, Hatemi I, Aydin I, Buyru N (2012) NPRL2 gene expression in the progression of colon tumors. Genet Mol Res 11: 4810-4816.

Zhou J, Hayakawa Y, Wang TC, Bass AJ (2014) RhoA mutations identified in diffuse gastric cancer. Cancer Cell 26: 9-11.

This work is published under the standard license to publish agreement. After 12 months the work will become freely available and the license terms will switch to a Creative Commons AttributionNonCommercial-Share Alike 4.0 Unported License. 